tác dụng chống viêm dị ứng, và làm bền tế bào mast của cao đặc EZ trên thực nghiệm", Tạp chí Y hoc Viêt Nam, 445, tr 200-203.

4. Nguyển Mạnh Tuyển, Hà Vân Oanh, Phạm Thái Hà Vằn, "Đánh giá độc tính cấp và bán trường diễn của viên nang hố trợ điều trị eczema", Tạp chí Y học Việt Nam, 481 (1), tr. 51-56.

5. Lu H. (2015), "Study on the isolation of active constituents in Lonicera japonica and the mechanism of their anti-upper respiratory tract infection action in children", African health sciences, 15 (4), pp. 1295-1301.

6. Peng W., Ming Q., Han P., (2014), "Anti-allergic rhinitis effect of caffeoxyl xanthiazonosid isolated from fruits of Xanthiumstrumarium $L$. in rodent animals", Phytomedicine journal, 21 (6), pp. 824-829.

7. Shiraishi M., Miyamoto A. (2016) "Antagonistic Effects of Gingko biloba and Sophora japonica on Cerebral Vasoconstriction in Response to Histamine, 5-Hydroxytryptamine, U46619 and Bradykinin", The American journal of Chinese, 44 (8), pp. 1607-1625.

\title{
ĐÁNH GIÁ KẾT QUẢ PHẪU THUÂTT KẾT HỢP XƯƠNG NẸP KHÓA ĐIỀU TRI GÃY LIÊN MẤU CHUYỂN XƯƠNG ĐÙI Ở NGƯỜI CAO TUỔI
}

\author{
Trần Hưu Hiếu ${ }^{1}$, Phan Trung Quyết ${ }^{2}$
}

\section{TÓM TẮT}

Mục tiêu: Mô tả lâm sàng, chẩn đoán hình ảnh và đánh giá kết quả phẫu thuật kết hợp xương gãy liên mấu chuyển xương đùi bằng nẹp khóa tại bệnh viện đa khoa tỉnh Nam Định. Đối tượng và phương pháp: Nghiên cứu mô tả cắt ngang hồi cứu và tiến cứu bễnh nhân gãy liên mấu chuyển xương đùi đ̛̛̛̛̛̛̣c phẩu thuật kết hợp xương bằng nep khóa có sự hỗ trợ của C-arm tại Bệnh viện đa khoa tỉnh Nam Định trong thời gian từ tháng 01 năm 2019 đến tháng 06 năm 2020. Kết quả: 62 bệnh nhân được điều trị đều liền vết mổ kỳ đâu, xương về đúng vị trí giải phẫu. Kết quả xa theo dõi trên $51 / 62$ bệnh nhân với kết quả rất tốt và tốt 39/51 bệnh nhân (76,5\%), trung bình $9 / 51$ bệnh nhân $(17,6 \%)$, kém $3 / 51$ bệnh nhân $(5,9 \%)$. Kết luận: Phương pháp mổ kết hợp xương nẹp khóa là một phương pháp phấu thuật có nhiều ưu điểm, kết xương vững chắc giúp bệnh nhân phực hồi chức năng vận động sớm sau gãy liển mấu chuyển xương đùi. thuật.

Tỉ̛ khóa: kết hợp xương, liên mấu chuyển, phẫu

\section{SUMMARY \\ EVALUATING THE SURGERY RESULTS LOCKED PLATE BONE TO TREAT FRACTURE OF THE FEMUR'S TRANSVERSE TROCHANTER FOR THE ELDERLY}

Objectives: Clinical description, diagnostic imaging and evaluation of the results of combined surgery of the transverse trochanteric fracture of the femur with a locking brace at the Nam Dinh province general hospital. Subjects and methods: Retrospective and prospective cross-sectional study of patients with transtrophal fibula fracture who

\footnotetext{
${ }^{1}$ Trường Đại học Điều dưỡng Nam Định

${ }^{2}$ Bênh viện Đa Khoa tỉnh Nam Định

Chịu trách nhiệm chính: Trần Hữu Hiếu

Email: hieundun@gmail.com

Ngày nhận bài: 16.3.2021

Ngày phản biên khoa học: 11.5.2021

Ngày duyệt bài: 19.5.2021
}

underwent ostomy with locking brace with the support of C-arm at Nam Dinh Provincial General Hospital during the period from January 2019 to June 2020. Results: 62 treated patients all healed the first incision, the bones returned to the correct anatomical position. Long-term follow-up on 51/62 patients with very good and good results $39 / 51$ patients $(76.5 \%)$, average $9 / 51$ patients $(17.6 \%)$, poor $3 / 51$ patients (5.9\%). Conclusion: The surgical method combined with the locking brace is a surgical method with many advantages, with a solid bone structure that helps patients recover early motor function after fracture of the transverse transverse femur.

Keywords: bone fusion, transverse trochanter, surgery.

\section{I. ĐẶT VẤN ĐỀ}

Vùng liên mấu chuyển xương đùi là vùng giữa hai mấu chuyển lớn và nhỏ, hoàn toàn là xương xốp, tất cả các đường gãy xương nằm trong vùng liên mấu chuyển xuống $2,5 \mathrm{~cm}$ dưới mấu chuyển nhỏ và $5 \mathrm{~cm}$ dưới mấu chuyển lớn được gọi là gãy liên mâu chuyển xương đùi. Đây là loại gãy xương khá phổ biến, chiếm $55 \%$ các loại gãy đâu trên xương đùi; hay xảy ra ở người cao tuổi, phụ nữ nhiều gấp 2-3 lân nam giới. Nguyên nhân là do loãng xương, có thể gây gãy xương chỉ do một chấn thương nhẹ như trượt chân ngã, tai nạn giao thông, tai nạn sinh hoạt. Trước đây, với gãy LMC xương đùi ở người cao tuổi chủ yếu được điều trị bảo tồn (như kéo nắn bó bột, xuyên đinh kéo liên tục...) gây nhiêuu biến chứng do bệnh nhân phải nẳm lâu như: loét tì đè, viêm phổi, viêm đường tiết niệu ảnh hưởng đến sức khỏe và tính mạng, nhất là các bệnh nhân tuổi cao, sức khỏe yếu.

Ngày nay, quan điểm điêuu trị gãy liên mấu chuyển xương đùi bằng phẫu thuật đã được thống nhất chấp nhận, nhằm phục hồi giải phẫu, tạo điêu kiện cho liền xương sớm, bệnh nhân 
sớm ngồi dậy và phục hồi chức năng đi lại được, tránh các biến chứng do nằm lâu. Tuy nhiên vẫn còn nhiều ý kiến chưa thống nhất trong việc lựa chọn kỹ thuật phẫu thuật như kết hợp xương hay thay khớp; loại phương tiện nào là thích hợp dùng trong kết hợp xương.

Tại Bệnh viện đa khoa tỉnh Nam Định, gãy liên mấu chuyển xương đùi có nhiều lựa chọn kỹ thuật phẫu thuật như thay khớp hoặc kết hợp xương (đóng đinh nội tủy, nẹp DHS, nẹp uốn, nẹp khóa) đối với các trường hợp gãy liên mấu chuyển thuộc phân loại $A 2$ hoặc $A 3$, theo phân loai của AO/ASIF. Mỗi kỹ thuật phẫu thuâtt đều có những ưu điểm và nhược điểm riêng. Nhưng kết hợp xương bằng nẹp khóa có ưu điểm là các vít được bắt cố định vào nẹp ở một góc cố định mang lại sự vững chắc cho cấu trúc giải phẫu mà không phụ thuộc vào lực ma sát giữa vít - nẹp xương tạo nên sự vững chắc cho khối mấu chuyển. Chúng tôi tiến hành nghiên cứu này nhằm mô tả lâm sàng, chẩn đoán hình ảnh và đánh giá kết quả phẫu thuật kết hợp xương gãy liên mấu chuyển xương đùi bằng nẹp khóa.

\section{II. ĐỐI TƯỢNG VÀ PHƯƠNG PHÁP NGHIÊN CỨU}

1. Đối tượng nghiên cứu. Gồm 62 bệnh nhân gãy liên mấu chuyển xương đùi được phẫu thuật kết hợp xương bằng nẹp khóa có sự hỗ trợ của C-arm tại Bệnh viện đa khoa tỉnh Nam Định trong thời gian từ tháng 01 năm 2019 đến tháng 06 năm 2020.

- Tiêu chuẩn lứa chọn: Bệnh nhân từ 60 tuổi trở lên, bị gãy kín liển mấu chuyển xương đùi, được phẫu thuật kết xương nẹp khóa có sự hỗ trợ của máy C-arm

\section{- Tiêu chuấn loai trư:}

+ Gãy liên mấu chuyển xương đùi do bệnh lý.

+ Bệnh nhân bị liệt không đi lại được trước khi gãy liên mấu chuyển xương đùi.

+ Phẫu thuật không sử dụng nẹp khóa, không có sự hỗ trợ của C-arm

+ Bệnh loãng xương độ 1,2.

\section{Phương pháp nghiên cứu}

2.1. Thiết kế nghiên cứu. Nghiên cứu mô tả cắt ngang hồi cứu và tiến cứu.

\subsection{Thu thập số liệu nghiên cứu}

\subsubsection{Nghiên cứu hồi cứu}

- Thu thập hồ sơ bệnh án, những tài liệu lưu trữ của BN nằm trong đối tượng nghiên cứu.

- Các bước tiến hành nghiên cứu: hồi cứu hồ sơ bệnh án của BN theo đối tượng nghiên cứu; thực hiện kiểm tra kết quả bằng mời khám lại, khám theo hẹn.

- Khám lâm sàng những BN đã được lựa chọn

\section{trong nghiên cứu.}

\subsubsection{Nghiên cứu tiến cứu}

- Khám bệnh, chụp Xquang

- Phân loại theo nhóm tuổi, giới, nguyên nhân chấn thương, mức độ tổn thương (sử dụng phân loại của $A O / A S I F)$, bệnh lý khác kèm theo cần điều trị, loại nẹp vis sẽ sử dụng, ngày phẫu thuật.

- Tham gia phẫu thuật.

- Điều trị theo dõi và hướng dẫn BN tập luyện sau phẫu thuật để đánh giá kết quả gần, biến chứng gần và kết quả xa.

- Thu thập số liệu thực tế BN nằm trong đối tượng nghiên cứu.

- Chụp Xquang kiểm tra ngay sau mổ để lấy tài liệu đánh giá kết quả.

2.3. Đánh giá kết quả. Kết quả nghiên cứu được đánh giá theo các tiêu chuẩn sau:

* Đánh giá kết quả gân:

- Lượng máu truyền, ngày nằm viện.

- Tình trạng toàn thân, tại vết mổ.

- Kết quả kết hợp xương (căn cứ trên phim Xquang):

+ Kết quả chỉnh trục xương, đặc biệt là góc cổ - thân xương đùi, xương di lệch thứ phát.

\section{Biến chứng:}

- Toàn thân: viêm phổi, viêm đường tiết niệu, suy kiệt, loét tỳ đè, tử vong trong tuần đầu, 3 tháng đầu sau phẫu thuật...

- Tại chỗ: chảy máu vết mổ, tụ dịch vết mổ, nhiễm khuẩn vết mổ, rò...

- Tuột, gãy, bật phương tiện kết hợp xương.

- Khồng liền xương, khớp giả.

*Đánh giá kết quả xa

- Đánh giá kết quả liền xương.

- Đánh giá mức độ phục hồi chức năng: theo phương pháp đánh giá của Merle d'Aubigné - Postel

2.4. Phương pháp phân tích và xử lý số liệu. Các dữ liệu được thu thập theo mẫu bệnh án nghiên cứu, xử lý thống kề theo phần mềm SPSS 20.0

Dùng kiểm định t-test để so sánh 2 trị số trung bình; kiểm định X2 so sánh 2 tỷ lệ phần trăm.

\section{KẾT QUẢ NGHIÊN CỨU}

1. Đặc điểm lâm sàng và chẩn đoán hình ảnh

- Trong 62 BN, chúng tôi thấy nhóm tuổi từ 80 tuổi trở lên chiếm tỷ lệ cao nhất $(54,8 \%)$ và nhóm tuổi từ 70 - 79 chiếm vị trí thứ $2(37,1 \%)$. Độ tuổi trung bình trong nghiên cứu là $80,3 \pm$ 7,95; tuổi thấp nhất là 62 tuổi, lớn nhất là 94 tuổi.

- Nguyên nhân gãy LMC xương đùi gặp nhiều nhất do tai nạn sinh hoạt $(85,5 \%)$, tiếp theo là tai nạn giao thông $(12,9 \%)$ và tai nạn lao động $(1,6 \%)$. 
Bảng 1. Phân loại gãy LMC dựa theo hinh ảnh $X$ quang $(n=62)$

\begin{tabular}{|c|c|c|c|}
\hline \multicolumn{2}{|c|}{ Loại gãy } & $\mathbf{n}$ & $\mathbf{\%}$ \\
\hline \multirow{3}{*}{$\mathrm{A} 1$} & $\mathrm{~A} 1.1$ & 0 & 0 \\
\cline { 2 - 4 } & $\mathrm{A} 1.2$ & 2 & 6,5 \\
\cline { 2 - 4 } & $\mathrm{A} 1.3$ & 8 & 12,9 \\
\hline \multirow{3}{*}{$\mathrm{A} 2$} & $\mathrm{~A} 2.1$ & 13 & 21,0 \\
\cline { 2 - 4 } & $\mathrm{A} 2.2$ & 7 & 11,3 \\
\cline { 2 - 4 } & $\mathrm{A} 2.3$ & 10 & 16,1 \\
\hline \multirow{3}{*}{$\mathrm{A} 3$} & $\mathrm{~A} 3.1$ & 8 & 12.9 \\
\cline { 2 - 4 } & $\mathrm{A} 3.2$ & 6 & 9,7 \\
\cline { 2 - 4 } & $\mathrm{A} 3.3$ & 8 & 12,9 \\
\hline \multicolumn{2}{|c|}{ Tống } & $\mathbf{6 2}$ & $\mathbf{1 0 0 . 0}$ \\
\hline
\end{tabular}

Loại gãy xương chủ yếu là loại $A 2, A 3(52 / 62$ BN chiếm $83,9 \%$ ), điều này cũng phù hợp với tiêu chuẩn lựa chọn $B N$, vì $B N$ trong nghiên cứu của chúng tôi là người cao tuổi, loãng xương với các mức độ khác nhau nên khi gãy xương thường là gãy không vững, có nhiều mảnh rời.

Bảng 2. Phân loại mức độ loãng xương theo Singh $(n=62)$

\begin{tabular}{|c|c|c|}
\hline Độ loãng xương & $\mathbf{n}$ & $\mathbf{\%}$ \\
\hline 1 & 0 & 0 \\
\hline 2 & 0 & 0 \\
\hline 3 & 14 & 22,6 \\
\hline 4 & 25 & 40,3 \\
\hline 5 & 19 & 30,6 \\
\hline 6 & 4 & 6,5 \\
\hline Tống & $\mathbf{6 2}$ & $\mathbf{1 0 0}$ \\
\hline
\end{tabular}

Trong tổng số $62 \mathrm{BN}$ nghiên cứu, có $14 \mathrm{BN}$ $(22,6 \%)$ bị loãng xương độ 3 và 4 BN $(6.5 \%)$ được xếp loại loãng xương độ 6 theo phân loại của Signh; BN bị loãng xương rất nặng (độ 1,2) không nằm trong đối tượng nghiên cứu

Bảng 3. Bệnh lý mạn tính kèm theo

\begin{tabular}{|c|c|c|}
\hline Các bệnh lý kèm theo & $\mathbf{n}$ & $\mathbf{\%}$ \\
\hline Tiếu đường & 16 & 25,8 \\
\hline Tim mạch & 19 & 30,6 \\
\hline Hồ hầp & 14 & 22,6 \\
\hline Bệnh khác & 8 & 12,9 \\
\hline
\end{tabular}

- Các BN nghiên cứu đều là người cao tuối, có không ít BN có một hoặc nhiều bệnh nội khoa man tính kèm theo như bệnh tim mạch, bệnh tiểu đường, bệnh hô hấp, gút...

\section{Kết quả điều trị}

- Phương pháp vô cảm: Trong 62 BN nghiên cứu thì 59/62 BN được vô cảm bằng phương pháp gây tê tủy sống chiếm tỷ lệ $95,2 \%$. Có 3 trường hợp phải gây mê nội khí quản (2 BN bệnh phổi mãn tính và $1 \mathrm{BN}$ gù vẹo cột sống).

- Phương tiện kết hợp xương: dùng nẹp vít khóa. Loại nẹp hay dùng nhất có 6 lỗ vít (dùng cho $56 / 62$ BN chiếm 90,3\%).

\subsection{Kết quả gân}

- Tai chỗ vết mổ: $100 \%$ BN đều có tình trạng vết mổ khô, liền da kỳ đầu, không có $B N$ nào bị nhiễm trùng vết mổ hoặc còn dịch.

- Toàn thân: Có 3 BN bị viêm phổi, 1 BN viêm đường tiết niệu được hội chẩn điều trị ổn định, có 1 BN huyết khối tĩnh mạch sâu, khồng có BN nào loét do tỳ đè hoăc chảy máu sau mổ.

- Trục xương: kiểm tra hình ảnh $X$ quang sau mổ thấy các nepp, vis ở vị trí đạt yêu câu; xương được cố định tốt, đúng vị trí giải phẫu

- Thời gian nằm viện trung bình của bệnh nhân là 7,8 \pm 2,3 (4-18) ngày.

\subsection{Kết quả xa}

- Có 54/62 BN đủ thời gian theo dõi xa sau mổ 6 tháng, kết quả kiểm tra cho thây $3 / 54$ trường hợp đã tử vong. Tổng số BN đủ điều kiện đánh giá xa là $51 \mathrm{BN}$. Thời gian theo dõi xa trung bình là 9,3 2,7 tháng(ngắn nhất 6 tháng, dài nhất 20 tháng)

- Có $12 / 51$ BN $(23,6 \%)$ đi lại bình thường, không đau; 23/51BN (45,1 \%) sinh hoạt bình thường, thi thoảng đau khi gắng sức; $2 / 51 \mathrm{BN}$ (3.9 \%) không đi lại được. Số còn lại đi lại cần có sự hỗ trợ ở các mức độ khác nhau.

Bảng 4. Đánh giá biên độ vận động khớp háng( $(n=51)$

\begin{tabular}{|c|c|c|}
\hline $\begin{array}{c}\text { Biên độ vận động khớp } \\
\text { háng }\end{array}$ & $\begin{array}{c}\text { Số } \\
\text { BN }\end{array}$ & $\begin{array}{c}\text { Tỷ lệ } \\
(\mathbf{\%})\end{array}$ \\
\hline $\begin{array}{c}\text { Bình thường và gân bình } \\
\text { thương, gấp háng }>90^{\circ}\end{array}$ & 17 & 33,3 \\
\hline Hạn chế gấp còn $80^{0}-90^{\circ}$ & 20 & 39,2 \\
\hline Hạn chế gấp còn $60^{\circ}-80^{\circ}$ & 6 & 11,8 \\
\hline Hạn chế gấp còn $40^{\circ}-60^{\circ}$ & 5 & 9,8 \\
\hline Gấp háng dưới $40^{\circ}$ & 3 & 5,9 \\
\hline Tổng & $\mathbf{5 1}$ & $\mathbf{1 0 0}$ \\
\hline
\end{tabular}

- Tình trạng ngắn chi: Sau phẫu thuật, có $39 / 51 \mathrm{BN}(76.5 \%)$ phục hồi chiều dài chi về bình thường, không ngắn hoă̆c ngắn chi dưới $1 \mathrm{~cm}$. Có $10 / 51$ BN $(19,6 \%)$ ngắn chi từ $1-2 \mathrm{~cm}$. Có 2 trường hợp ngắn chi $>3 \mathrm{~cm}$.

Bảng 5. Kêt quá xa theo loại gãy $\operatorname{LMC}(n=51)$

\begin{tabular}{|c|c|c|c|c|c|c|c|}
\hline \multirow{3}{*}{ Kết quả } & \multicolumn{6}{|c|}{ Phấn loại gãy } & \multirow{3}{*}{ Tổng } \\
\hline & \multicolumn{2}{|c|}{ Loại A1 } & \multicolumn{2}{|c|}{ Loại A2 } & \multicolumn{2}{|c|}{ Loại A3 } & \\
\hline & $\mathbf{n}$ & $\%$ & $\mathbf{n}$ & $\%$ & $\mathbf{n}$ & $\%$ & \\
\hline Rất tốt & 6 & 33,3 & 9 & 50,0 & 3 & 16.7 & 18 \\
\hline Tốt & 2 & 9,5 & 15 & 71,4 & 4 & 19.1 & 21 \\
\hline Trung bình & 0 & 0 & 4 & 44.4 & 5 & 55,6 & 9 \\
\hline
\end{tabular}


VIETNAM MEDICAL JOURNAL N¹ - JUNE - 2021

\begin{tabular}{|c|c|c|c|c|c|c|c|}
\hline Kém & 0 & 0 & 1 & 33,3 & 2 & 66,7 & 3 \\
\hline Tống & $\mathbf{8}$ & \multicolumn{2}{|c|}{0.205} & $\mathbf{1 9}$ & & $\mathbf{5 1}$ \\
\hline$p$ & \multicolumn{2}{|c|}{0} \\
\hline
\end{tabular}

So sánh giữa các nhóm thấy tỷ lệ tốt và rất tốt ở nhóm A1 đat cao hơn cả ( $100 \%)$, tiếp đến ở nhóm A2 (95.7\%) và nhóm A3 (66.7\%). Song vì số liệu từng nhóm ít nên khi so sánh thống kê X2 thì chưa có sự khác biệt có ý nghĩa giữa các nhóm $(p>0,05)$.

2.3. Kết quả chung. Dựa vào kết quả khám lâm sàng, $X$ quang và thang điểm của Merle d'Aubigné - Postel, chúng tôi có bảng phân loại đánh giá kết quả xa như sau:

Bảng 6. Kết quả chung $(\boldsymbol{n}=\mathbf{5 1})$
\begin{tabular}{|c|c|c|}
\hline Phân loại kết quả & Số BN & Tỷ lệ (\%) \\
\hline Rất tốt & 18 & 35,3 \\
\hline Tốt & 21 & 41,2 \\
\hline Trung bình & 9 & 17,6 \\
\hline Kém & 3 & 5.9 \\
\hline Tống & $\mathbf{5 1}$ & $\mathbf{1 0 0}$ \\
\hline
\end{tabular}

\section{BÀN LUẬN}

Tỉ lệ $B N$ nũ gãy $L M C$ xương đùi cao hơn $B N$ nam do đăc điểm mức độ loãng xương ở BN nữ cao tuổi nặng nề hơn BN nam, bên canh đó tuổi tho trung bình của nữ giới cũng cao hơn nam giới. Trong nghiên cứu này, tuối trung bình tại thời điểm phẩu thuât là $80,3 \pm 7.95$ (đô tuổi thấp nhất là 62 tuổi - cao nhất là 94 tuổi), BN nam có $23 \mathrm{BN}$ chiếm $37,1 \%$ trong khi có $39 \mathrm{BN}$ nữ $(62,9 \%)$. Kết quả này cũng phù hợp với đa số nghiên cứu [1], [4], [5], [6].

Trong nghiên cứu của chúng tôi, nguyên nhân gãy LMC do TNSH là thường gặp nhất $(85,8 \%)$. Cơ chế chấn thương thường gặp nhất là ngã đập vùng mông xuống nền cứng (nền nhà, bậc thềm, sân giếng, nền nhà vệ sinh...). Điều này phản ánh đúng thực tế vì người cao tuổi $(\geq 60)$ đều có loãng xương tuổi già, chỉ cần môt lực chấn thương nhe cũng đã có thể gây gãy xương. Mấu chuyển xương đùi là một vùng xương xốp, là nơi thay đổi về hình thể nên khi có loãng xương thì đây là một điểm yếu dễ xảy ra gãy xương.

Sau mổ, kết quả gần cho thấy, khi ra viện tất cả 62 BN đều có tình trạng vết mổ khô, không có $\mathrm{BN}$ nào bị nhiễm trùng vết mổ hoặc còn dịch. Không có $\mathrm{BN}$ nào tử vong trong thời gian nằm viện; có $3 \mathrm{BN}$ bị viêm phổi, 1 BN viêm đường tiết niệu đã được hội chẩn, điều trị ổn định trước khi ra viện. Không có trướng hợp nào bị loét do tỳ đè hoặc chảy máu sau mổ.

Trong nghiên cứu của chúng tôi, $\mathrm{BN}$ nằm viện ngắn nhất là 4 ngày, dài nhất là 18 ngày, thời gian nằm viện trung bình là $7,8 \pm 2,3$ ngày. Có 32 $\mathrm{BN}$ nằm viện dưới 7 ngày $(51,6 \%)$, có $27 / 62 \mathrm{BN}$ nằm viện từ $7-15$ ngày. Có $3 \mathrm{BN}$ nằm viện trên 15 ngày. Những trường hợp phải nằm lâu là do bệnh lý nội khoa kèm theo và thương tổn phối hợp nặng nề cần phải được điều trị ổn định.

Khả năng đi lại sau mổ: kiểm tra kết quả xa từ sau điều trị 6 tháng đến 20 tháng được 51 BN. Trên lâm sàng thây $18 / 51$ BN $(35,3 \%)$ đi lại bình thường, 15/51 BN $(29,4 \%)$ đi lại tập tễnh, đau khi gắng sức; $11 / 51$ BN $(21,6 \%)$ đi lại phải dùng nạng, thường phải dùng thuốc giảm đau; có 7 BN đi lại khó khăn hoă̆c không đi lại được. Khả năng đi lại kém do tuổi cao cơ lực kém, bất động lâu ngày tập luyện không thường xuyên do không có ai chăm sóc, tình trạng loãng xương tiến triển nặng, các bệnh mãn tính diễn biến...

Đánh giá biên độ vận động khớp háng: Có 17/51 BN (33.3\%) có biên độ vận động khớp háng bình thường, gấp háng lởn hơn 90 độ. Có 26/51 BN biên độ vân động khớp háng hạn chế nhẹ và vừa. Hạn chế vận động gấp háng nặng được ghi nhận có 8 BN $(15,7 \%)$. Biên độ vận động khớp háng cũng như khả năng đi lại phụ thuộc vào nhều yếu tố như đã nêu trên.

Ngắn chân sau phẫu thuật:Trong nghiên cứu của chúng tôi có $39 / 51$ BN $(76.5 \%)$ phục hồi chiều dài chi về bình thường, không ngắn hoă̆c ngắn chi dưới $1 \mathrm{~cm}$. Có $10 / 51$ BN $(19,6 \%)$ ngắn chi từ $1-2 \mathrm{~cm}$. Có 2 trường hợp ngắn chi $>3 \mathrm{~cm}$, là 2 BN loãng xương độ 3, gãy loại $A 2-3$ và $A 3-2$ đi lại sớm sau mổ.

Kết quả xa theo dõi trên $51 / 62$ bênh nhân với kết quả rất tốt và tốt $39 / 51$ bệnh nhân (76,5\%), trung bình $9 / 51$ bệnh nhân $(17,6 \%)$, kém $3 / 51$ bênh nhân $(5,9 \%)$. So sánh với môt số công trình nghiên cứu về điêu trị gãy LMC xương đùi của các tác giả:

Mai Châu Thu (2004)[2] điều trị 54 BN gãy LMC xương đùi bằng $\mathrm{KHX}$ nẹp góc $\mathrm{AO} 130^{\circ}$ có sử dụng màn tăng sáng và bàn mổ chỉnh hình, kết quả rất tốt và tốt 82,4\%; trung bình 14,7\%; kém 2,9\%

Trần Quang Toản(2008)[3], điêuu trị 45 BN gãy LMC xương đùi bằng phương pháp kết xương nẹp DHS không sử dụng màn tăng sáng và bàn mổ chỉnh hình, kết quả chung rất tốt và tốt $88,5 \%$; trung bình 11,5\%; không có kết quả kém.

So sánh với kết quả nghiên cứu với các tác giả trước, nhận thấy kết quả thu được trong điều trị gãy vùng LMC xương đùi bằng kết xương nẹp 
khóa tại Bệnh viện đa khoa tỉnh Nam Định là một kết quả tốt, rất đáng khích lệ.

So sánh giữa các nhóm thây tỷ lệ tốt và rất tốt ở nhóm A1 đạt cao hơn cả (100\%), tiếp đến ở nhóm A2 (95.7\%) và nhóm A3 (66.7\%). Song vì số liệu từng nhóm ít nên khi so sánh thống kê X2 thì chưa có sự khác biệt có ý nghĩa giữa các nhóm ( $p>0,205)$.

Kết quả xa còn phụ thuộc vào các yếu tố như vận động sau mổ, sự hợp tác tuân thủ chế độ tập tại nhà cũng như điều kiện sức khỏe và độ tuổi của bệnh nhân có ảnh hưởng lớn đến kết quả điều trị.

\section{KẾT LUẬN}

Phương pháp kết hợp xương gãy liên mấu chuyển xương đùi bằng nẹp khóa là phương pháp kết xương vững chắc cho phép vận động và phục hồi chức năng sớm tránh được các biến chứng do bệnh nhân nằm lâu.

Đặc biệt đối với các bệnh nhân cao tuổi, có bệnh lý nội khoa kèm theo cân điều trị tích cực các bệnh nội khoa cũng như hướng dẫn bệnh nhân, người nhà tập phục hổi chức năng để đạt kết quả tốt.

\section{TÀI LIẸU THAM KHẢO}

1. Nguyễn Đắc Nghĩa (2006), Lưa chọn kỹ thuật điêu trị gãy đâu trên xương đùi ở người cao tuổi xem lại y văn, Tạp chí Y Dược học lâm sàng 108 , Số đăc biêt, 114-118.

2. Mai Châu Thu (2004), Đánh giá kết quả điều trị phẫu thuất gãy vùng mấu chuyển xương đùi ngườ lớn bằng nẹp gập góc liền khối tại bệnh viện Xanh pôn 2002-2004. Luận văn Bác sỹ் chuyên khoa II, Hoc viện Quân y.

3. Trần Quang Toản (2008), Đánh giá kết quả điều trị phẩu thuật gãy vùng mấu chuyển xương đùi người lớn bằng kết xương nẹp DHS tại bệnh viện Xanh pôn. Luận văn Thạc sỹ Y học, Học viện Quân y.

4. Lindskog D.M, Baumgaertner M.R (2004), Unstable Intertrochanteric hip Fractures in the Elderly, J. Am Acad Orthop Surg, 12, 179-190.

5. Nikunj Maru, Kishor Sayani (2013), Unstable Intertrochanteric Fractures In High Risk Elderly Patients Treated With Primary Bipolar Hemiarthroplasty: Retrospective Case Series, Gujarat Medical Journal, 68(2).

6. Erik N. Kubiak E. F., Eric S. and Kenneth A. (2006), The Evolution of Locked Plates, J. Bone Joint Surg, 88, 189-200.

\title{
ĐĂC ĐIỂM LÂM SÀNG VÀ CẬN LÂM SÀNG CỦA 612 BỆNH NHÂN XUẤT TINH MÁU TẠI BỆNH VIỆN ĐẠI HỌC Y HẦ NộI
}

\author{
Trần Phước Duy Bảo ${ }^{1}$, Lê Quốc Hưng ${ }^{2}$, Nguyễn Hoài Bắc ${ }^{2}$
}

\section{TÓM TẮT}

Để nhận biết các đặc điểm lâm sàng, cận lâm sàng của tình trạng xuất tinh máu ở nam giới, chúng tôi tiến hành nghiển cứu trên 612 bênh nhân nam bị xuất tinh máu. Kết quả cho thấy tuổi trung bình của các bệnh nhân trong nghiên cứu là 39,42 $\pm 11,67$ tuổi. Tỉ lệ bệnh nhân có tiên sử sử dụng rượu bia trong những lần xuất tinh có máu chiếm 22,45\%, tỉ lệ bệnh nhân ghi nhận có thói quen kìm hãm hay gián đoạn quan hệ khi xuất tinh chiếm 16,25\%. Tỉ lê bệnh nhân làm PCR lao dương tính chiếm $1,27 \%$. Tỉ lệ bệnh nhân có tPSA tăng chiếm $1,92 \%$. Tî lệ nuôi cấy dương tính chiếm $8,94 \%$. Nồng độ testosterone ở những bệnh nhân này khá thấp so với lứa tuổi, trong đó có $26,01 \%$ bệnh nhân có giá trị testosterone giảm ( $<12,1 \mathrm{nmol} / \mathrm{L}), 23,7 \%$ bệnh nhân có giá trị testosterone trong giới hạn thẩp $(12,1-15$

\footnotetext{
${ }^{1}$ Bệnh viện Đa khoa khu vực Thủ Đức

${ }^{2}$ Trường Đại học Y Hà Nội

Chịu trách nhiệm chính: Trân Phước Duy Bảo

Email: drduybao.dkkvthuduc@gmail.com

Ngày nhận bài: 17.3.2021

Ngày phản biên khoa học: 10.5.2021

Ngày duyệt bài: 19.5.2021
}

nmol/L). Tư khóa: Xuất tinh máu, yếu tố nguy cơ xuất tinh ra máu.

\section{SUMMARY}

\section{CLINICAL AND SUBCLINICAL CHARACTERISTICS OF 612 PATIENTS WITH HEMATOSPERMIA AT HANOI} MEDICAL UNIVERSITY HOSPITAL

To identify the clinical and subclinical features of hemospermia in men, we conducted a study on 612 male patients with hemospermia. The results showed that the average age of the patients in the study was $39.42 \pm 11.67$ years. Proportion of patients with a history of alcohol use in blood-occupied ejaculations $22.45 \%$, the proportion of patients reporting a habit of delaying or interrupting when ejaculation is occupied $16.25 \%$. The proportion of patients with positive PCR test for tuberculosis accounted for $1.27 \%$. The proportion of patients with tPSA increased by $1.92 \%$. The positive culture rate accounts for $8.94 \%$. The testosterone levels in these patients were quite low for age, of which $26.01 \%$ had decreased testosterone values $(<12.1 \mathrm{nmol} / \mathrm{L})$, and $23.7 \%$ had low testosterone values $12.1-15 \mathrm{nmol} / \mathrm{L})$. factors.

Keywords: Hematospermia, hematospermia risk 